\title{
CONVERGÊNCIA E COMPLEMENTARIDADE ENTRE AS VERTENTES DE PROTEÇÃO INTERNACIONAL DOS DIREITOS HUMANOS
}

\author{
CONVERGENCE AND COMPLEMENTARITIES OF INTERNATIONAL \\ PROTECTION OF HUMAN RIGHTS' TOOLS
}

\author{
Vera Cecília Abagge de Paula* \\ Carol Proner**
}

RESUMO: As normas de Proteção Internacional da Pessoa Humana, amplíssimo leque de disposições consagradas em declarações e pactos, internalizadas em constituições e leis e garantidas por órgãos e organismos nacionais, supranacionais e não-governamentais, devem ser consideradas a partir do seu objetivo comum, de proteger o ser humano em quaisquer circunstâncias e a qualquer tempo, aplicando convergentemente suas especificidades no sentido da mais ampla proteção. Neste $60^{\circ}$ aniversário da Declaração Universal dos Direitos Humanos, não há quem discorde em compreender o "consenso universal" de 1948 recontextualizado, atualizado a partir das conquistas hermenêuticas dos anos que se seguiram. A Declaração Universal - e principalmente a contradição dos tempos da Guerra Fria e do estabelecimento de dois Pactos Internacionais separados em 1966 - desloca-se de seu marco histórico, transforma-se e atualiza-se a partir da experimentação prática e da constatação que as garantias apenas no plano formal não apenas são insuficientes como, por vezes, desviam a atenção e dissipam energia rumo à efetividade. PALAVRAS-CHAVE: direitos humanos; direito humanitário; proteção internacional da pessoa humana.

* Mestre e Doutora em Direito pela UFRJ, Professora Associado II em Direito Internacional Público da UFPR.
ABSTRACT: The norms of International Protection of Human Being, a very wide range of dispositions established in statements and treaties, internalized in constitutions and laws assured by national, supranational, and non-governmental agencies and organizations, must be considered from their common goal of protecting human being under any circumstances and at any time, by applying jointly their specifications in the sense of the widest protection. On this $60^{\text {th }}$ anniversary of Universal Declaration of Human Rights, there is no one who disagrees in understanding "universal consensus" of 1948 re-contextualized, updated from hermeneutical conquests of the years that followed. The Universal Declaration - and mainly the contradiction of Cold War times and the settlement of two separate International Treaties in 1966 - gets away from its historic milestone, changes and updates from the practical experimentation and substantiation that the guarantees only on the formal plan are not only insufficient but also sometimes they divert attention and dissipate energy toward effectiveness.

KEYWORDS: human rights; humanitarian law; international protection of human being.

**Mestre e Doutora em Direito Internacional e Professora do Programa de Mestrado em Direito da UniBrasil e do Programa Máster Oficial em Direitos Humanos, Interculturalidade e Desenvolvimento da Universidade Pablo de Olavide, Sevilha. 


\section{INTRODUÇÃO}

A disciplina do direito internacional humanitário costuma ser menos trabalhada nos currículos jurídicos se comparada à disciplina do direito internacional dos direitos humanos. Os atuais programas de formação acadêmica em direito já superaram certo descaso para com o estudo das normas internacionais de proteção dos direitos humanos, mas ainda persiste a separação dos ramos ou vertentes de proteção internacional da pessoa humana (direitos humanos, direito humanitário, direito dos refugiados).

A tese das vertentes foi exposta por Antônio Augusto Cançado Trindade na obra Tratado de Direito Internacional dos Direitos Humanos. $\mathrm{O}$ autor explica a necessidade de superar a visão compartimentalizada resgatando o objetivo comum de aplicação das normas: a proteção do ser humano em todas e quaisquer circunstâncias. O autor faz a ressalva de que convergência não se traduz em uniformidade. As vertentes são complementares efetivamente porque suas regras são distintas e podem ser aplicadas em alternância ou superposição, substantiva ou processual, de acordo com a situação que se apresente. ${ }^{1}$

A superação acontece pouco a pouco no plano teórico e formal, mas é no plano empírico que a integração das vertentes precisa se dar, pois quando um direito humano é violado pouco importa que se trate de uma ou outra categoria. A urgência de restabelecimento das condições de

1 TRINDADE, A.A. Cançado. Tratado de Direito Internacional dos Direitos Humanos, volumes I, II e III. Editora Sérgio Antonio Fabris. 2003. humanidade deve conclamar todas as forças jurídicas ao mesmo tempo, cada qual oferecendo o máximo de instrumentos possíveis para atuar no caso concreto.

Certos direitos são consagrados amplamente na comunidade internacional e considerados inderrogáveis. São direitos que revelam situações graves nas quais o ser humano perde sua condição de humanidade e dignidade. Os debates sobre o estabelecimento de um rol mínimo de direitos capaz de comportar o conceito de dignidade humana são extensos. Não há consenso quando a interlocução envolve critérios de multiculturalismo, por exemplo, mas a comunidade internacional estabelece que alguns direitos não podem ser derrogados por lei interna, cultura específica, norma religiosa ou estado de exceção, entendendo-os como sine qua non para a condição de ser humano.

Em situação de conflito armado, entretanto, tais direitos são sumariamente desconsiderados. O direito à inviolabilidade da pessoa humana, o respeito à vida, à integridade física, mental e atributos da personalidade são os mais sensíveis e primeiros a sofrerem violação em um conflito armado. Não há possibilidade de concessões nesses casos. O direito internacional precisa dar resposta clara, censurando condutas que ultrajam esse rol de direitos e oferecendo soluções orientadas pelo critério da efetividade e não apenas da garantia de direitos.

Assim também ocorre com outros direitos inseridos no rol da inderrogabilidade: o princípio da não-discriminação, a garantia aos direitos humanos fundamentais em quaisquer circunstâncias, o princípio da segurança pessoal e da proibição da tortura, do tratamento cruel ou degradante, da 
detenção ou da prisão arbitrária e a observância do devido processo legal. No entanto, a configuração desses direitos no plano concreto depende da definição de quem sejam os sujeitos ativos e passivos da violação, em que território e sob quais condições ocorre e, sobretudo, quais os resultados derivados da prática violadora. Respondendo a perguntas como essas, orientado pelo princípio da mais ampla proteção e pela complementaridade, o direito internacional poderá ser instrumento de coibição à condutas antijurídicas e ação no sentido do restabelecimento de direitos.

\section{PRIMEIRA VERTENTE: DIREITO INTERNACIONAL DOS DIREITOS HUMANOS}

A primeira vertente, proteção internacional dos direitos humanos, tem origem comparativamente recente, tendo em vista as lutas e conquistas por reconhecimento dos direitos humanos no plano internacional (a construção de consensos, a positivação, a difusão e a implementação dos direitos no âmbito dos Estados). Parte da idéia de que o ser humano deve ser protegido contra as arbitrariedades do Estado.

A aplicação das normas dessa vertente subordina-se ao exercício soberano e ao desejo do Estado de participar dos consensos internacionais, vontade expressa em declarações, pactos e convenções internacionais no decorrer do século XX e que consolidaram uma visão universalista dos direitos humanos.

Contrariamente à idéia segundo a qual o Estado estaria abrindo mão de sua soberania ao participar do ambiente supranacional de aplicação de normas de direitos humanos, a soberania é exercida plenamente no momento em que ocorre a ratificação dos documentos internacionais e a aceitação das jurisdições supranacionais com competência para julgar o Estado. A fundamentação está na legitimidade desses grandes consensos a partir da meta conjunta de cooperação internacional e manutenção da paz. Às garantias constitucionais e internas que o ente estatal já possui, somam-se os consensos internacionais em matéria de direitos humanos, dotados dos avanços conquistados em fóruns e debates contemporâneos e que servem para atualizar as legislações nacionais.

Ato contínuo no sentido da corroboração e do caminho em direção à plena eficácia das normas internacionais, e como exercício do princípio da responsabilidade internacional, cabe ao Estado atualizar e harmonizar sua legislação interna, bem como criar mecanismos sancionadores e medidas preventivas para garantir o cumprimento dos compromissos assumidos.

$\mathrm{O}$ direito internacional dos direitos humanos compreende a síntese das dimensões ou também chamadas gerações de direitos humanos considerados a partir da superação de outra compartimentalização: os direitos humanos passam a ser considerados como direitos indissociáveis, interdependentes e complementares, abrangendo os meios social, político, econômico, cultural, civil, ambiental em dinâmicas sociais e processos de luta. Os direitos humanos superam concepções naturalistas e são compreendidos como processos, movimentos e lutas na busca por condições melhores de vida e de acesso a bens. ${ }^{2}$

HERRERA FLORES, Joaquín, La reinvención de los derechos humanos. Sevilla: Colección Ensayando, 2007. 
Os instrumentos internacionais estabelecem hipóteses de violação, na maioria dos casos por meio de dispositivos genéricos e abrangentes capazes de serem adaptados à multiplicidade das situações e das realidades dos diferentes Estados-parte. Não significa, no entanto, que o repertório fundamental do discurso presente no sistema universal dos direitos humanos esteja livre dos condicionamentos culturais dominantes. É fundamental lembrar que o consenso universal foi construído no compasso de outros consensos e que privilegiou uma visão abstrata e ocidental em detrimento da diferença, dos valores de outras culturas e, principalmente, da possibilidade de um sistema econômico e social de base igualitária. ${ }^{3}$

As normas de proteção internacional dos direitos humanos possibilitam reivindicação a qualquer tempo e em qualquer lugar, respeitando os limites de vinculação do Estado ao direito internacional.

A característica mais importante dessa vertente de proteção da pessoa humana é a possibilidade de o indivíduo possuir legitimidade ativa para denunciar uma violação de direitos humanos. O direito de petição individual reveste-se de simbologia e representa um dos mais importantes avanços já na matéria. $\mathrm{O}$ direito a reportar-se a um tribunal supranacional faz do indivíduo um sujeito ativo de direito internacional, capaz de questionar o comportamento do Estado e de promover um processo de responsabilização internacional que, para além do caso concreto, constitui um precedente de aplicação do direito internacional e de expectativa de

3 PRONER, Carol. Direitos humanos e seus paradoxos: analise do sistema americano de proteção. Porto Alegre: Fabris, 2002. comportamento futuro. O direito internacional se renova com a participação de inéditos atores e, sobretudo, se democratiza e se humaniza.

O conjunto de normas internacionais de proteção dos direitos humanos costuma ser dividido em sistema universal, concernente ao conjunto de normas derivadas da Organização das Nações Unidas (ONU), e em sistemas regionais de proteção. A ONU simboliza o chamado consenso universal expresso na Declaração Universal de Direitos Humanos, de 1948 e nos Pactos Internacionais de $1966 .{ }^{4}$ O sistema universal revela-se um marco contraditório. Por um lado, simboliza a conquista de valores comuns, consensuais e a partir dos quais os sistemas regionais e nacionais passarão a ser estruturados, influenciados pelo desejo de paz e de cooperação internacional nascido no concerto do pós Segunda Guerra. Por outro lado, simboliza a eleição de valores culturais compatíveis com um mundo profundamente desigual. Mesmo com as releituras e as revisões trazidas pela Convenção de Viena de 1993, os direitos humanos pactuados tanto no sistema universal como nos sistemas regionais privilegiam direitos civis e políticos em detrimento dos direitos econômicos, sociais e culturais e estabelecem metas e expectativas em torno dos direitos de liberdade e de cidadania. ${ }^{5}$ A mesma

4 A Carta Internacional dos Direitos do Homem é constituída pela Declaração Universal dos Direitos do Homem, pelo Pacto Internacional sobre os Direitos Econômicos Sociais e Culturais e pelo Pacto Internacional sobre os Direitos Civis e Políticos e seu Protocolo Facultativo.

5 O conhecido Índice de Desenvolvimento Humano das Nações Unidas (IDH), criado por Mahbub ul Huq e que contou com a colaboraçao de Amarthia Sen, também contém a contradição de representar avanços, 
discriminação ocorre internamente, no plano dos direitos fundamentais do Estado, consagrados em cartas constitucionais, reproduzindo a operacionalidade do sistema político e econômico predominante.

Os sistemas regionais reproduzem essa mesma contradição, mas por representarem contextos geográficos mais restritos, apresentam vantagens em relação ao sistema universal no que diz respeito à aplicação. $\mathrm{O}$ sistema interamericano e o sistema europeu de proteção dos direitos humanos são considerados os modelos mais eficazes de aplicação de normas supranacionais, seja por seu estágio de desenvolvimento, seja pela participação e vontade política dos Estados membros.

O sistema europeu costuma ser considerado o mais avançado em relação aos procedimentos e ao entendimento comum dos atores estatais, tendo em vista que se trata de um sistema dentro de outros existentes, contaminados pela sinergia da União Européia. Os direitos do homem, as liberdades fundamentais e a democracia são valores definidos e defendidos pelo Conselho da Europa e pela Convenção Européia, valores que permeiam o Estatuto do Conselho da Europa e que representam critérios e valores reafirmados durante o

ao questionar o desenvolvimento econômico a partir de outros índices (humanos), mas não rompe com a limitaçao de desenvolvimento como acesso aos direitos de liberdade. De acordo com Teitelbaum, "un rasgo común entre Amatya Sen y dichos economista es el enfoque subjetivo, individualista, de la inserción del ser humano en la sociedad en general y en las relaciones económicas en particular. (...) Su fervor individualista y neoliberal le hace decir a Sen que la libertad permite a los individuos decidir lo que van a producir, olvidando que hace varios siglos que la producción es social y no individual." TEITELBAUM, Alejandro. La crisis actual del derecho al desarrollo. Deusto: Universidad de Deusto. Instituto de Derechos Humanos. 2001, p. 90. processo de abertura para a entrada de novos países.

A construção de um "Estado europeu", desejo político manifesto, passa necessariamente pelo aprimoramento do sistema de proteção de direitos humanos, mas nos últimos tempos o sistema aponta sinais de crise pela dificuldade em dar resposta às demandas encaminhadas, dentre as quais muitas por solicitação direta de particulares, especialmente após o alargamento da União Européia com a entrada dos países do Leste. As estatísticas demonstram um momento crítico e que inviabiliza o cumprimento do princípio da celeridade processual defendido pelo sistema supranacional desde a sua criação. Desde a entrada em funcionamento da Comissão Européia de Direitos Humanos (1955) e até o ano de 1998 foram registrados 44.056 pedidos. Desses, 5.006 foram apresentados no ano de 1998. A média anual de pedidos registrados foi de 444 , de 1975 a 1984, e atinge 3.102 casos de 1990 a 1998 (neste último ano foram mais de 5 mil petições). Atualmente são mais de 26 mil demandas em diferentes níveis de processamento. $^{6}$

O caso europeu demonstra que o direito internacional público precisa estar preparado para enfrentar relações para além do jurídico, situações que afetam as relações econômicas, políticas, sociais e culturais e que podem inclusive significar conflito de valores na eleição do rol de direitos humanos fundamentais.

6 Dados apresentados por Helio Bicudo, ex presidente da Comissão Interamericana de Direitos Humanos-OEA na Conferencia Magna Helio Bicudo, VII Conferencia Nacional dos Direitos Humanos. Congresso Nacional, Brasília, 2002. 
O sistema interamericano costuma igualmente ser considerado um sistema procedimental exitoso e sofisticado, inspirado no modelo europeu, mas com características próprias e que respeitam o contexto sul e centro-americanos. Os Estados dessas regiões são em parte responsáveis pela boa operacionalidade do sistema interamericano de proteção de direitos humanos, contribuindo a partir de sua vinculação aos documentos e órgãos existentes. No entanto, a chamada evolução do sistema interamericano advém em grande medida de uma jurisprudência atenta aos princípios da celeridade, oralidade, verdade dos fatos, ao esforço em reconhecer o jus standi, o direito do indivíduo de participar efetivamente em todos os momentos do processo, sem descuidar o princípio do devido processo legal.

A existência de competências específicas entre Comissão e Corte Interamericana, órgãos autônomos do sistema da Organização dos Estados Americanos, é atualmente apontada como vantagem comparativamente ao procedimento europeu e a opção desse sistema em reunir os órgãos de decisão existentes (Comissão, Corte e Comitê de Ministros do Conselho da Europa) transformando-os em um só órgão permanente: a Corte Européia dos Direitos do Homem. A reestruturação européia, como bem aponta Helio Bicudo, não mudou, fundamentalmente, o procedimento, já que persistem as fases de admissibilidade, conciliação e duplo exame do mérito. A Corte Européia passou a ser constituída de uma Câmara, formada por três juízes que passam a exercer as funções anteriormente atribuídas à Comissão: exame de admissibilidade, estabelecimento dos fatos, conciliação e decisão de mérito. Após o filtro do Comitê (que, por unanimidade, poderá declarar a petição inadmissível), a petição individual será encaminhada a uma Câmara de sete juízes que decidirá sobre sua admissibilidade e, depois de uma tentativa de conciliação, decidirá sobre o mérito. Essa decisão, porém, não é definitiva, pois uma das partes pode solicitar que o processo seja enviado a uma grande Câmara, de dezessete juízes. ${ }^{7}$

No caso do sistema interamericano, a Comissão Interamericana de Direitos Humanos exerce uma função quase jurisdicional, pois possui competência para receber as denúncias de violações que lhe são apresentadas pelas vítimas ou por quaisquer pessoas ou organizações não-governamentais, contra atos que violem a Declaração Americana de Direitos e Deveres do Homem, a Convenção Americana de Direitos Humanos e demais documentos do sistema OEA, inclusive o Protocolo Adicional à Convenção Americana em matéria de Direitos Econômicos, Sociais e Culturais.

A Comissão terá o papel de processar essas denúncias, filtrando os critérios de admissibilidade, procedendo ao seu exame e, depois de admiti-las, terá competência para fazer recomendações aos Estados e, ao final, decidirá quanto à pertinência de se apresentar o caso à Corte. Sendo assim, a Corte somente se pronunciará sobre os casos que lhe sejam apresentados pela Comissão ou por um Estado-parte, tendo sido filtradas e resolvidas grande parte das demandas por inadmissibilidade, por conciliação ou por

Conferencia Magna Helio Bicudo, VII Conferencia Nacional dos Direitos Humanos. Congresso Nacional, Brasília, 2002. 
recomendação da Comissão aceita e executada pelo Estado.

A Comissão realiza um procedimento processual e, embora não propriamente jurisdicional, trata-se de um exercício de natureza pública, parcialmente judicial, auxiliando a Corte Interamericana no papel de processar e julgar os Estados. A Corte é composta também por sete membros com as mesmas qualificações, com um mandato de seis anos (renovável por mais seis) e representa o órgão jurisdicional supremo, dotado de competência para julgar em última instância um Estado que tenha cometido uma violação de direitos humanos prevista nos documentos do sistema da OEA.

O sistema interamericano tem sido considerando não apenas exitoso no aspecto procedimental, como também inovador e audacioso em respeito aos princípios da publicidade/acessibilidade, celeridade e, em especial, ao princípio da interdependência dos direitos humanos, com precedentes de casos que atingem, ainda que indiretamente, os direitos de natureza social, econômica e cultural. ${ }^{89}$

8 Em matéria de direitos econômicos, sociais e culturais, a Corte Interamericana de Direitos Humanos tem conduzido sua jurisprudência para dar tratamento adequado, superando a compartimentalização dos direitos em gerações e não se furtando em enfrentar a limitação essencial que enfrenta o sistema de proteção de direitos humanos a partir de uma concepção cultural e econômica.

9 Como exemplo do freqüente esforço do sistema interamericano por dar respostas as demandas da sociedade civil e dos Estados, no marco do LXXIV Período ordinário de sessões ( 22 de janeiro a 3 de fevereiro de 2007), decidiu-se modificar o formato das sentenças da Corte Interamericana de Direitos Humanos com o objetivo de reduzir o tamanho das sentenças de tal forma que venham a ser mais acessíveis ao público,
Outro sistema regional que conquista garantias importantes é o sistema africano, existente no marco da Organização da Unidade Africana (OUA). A Carta Africana sobre Direitos Humanos e dos Povos (conhecida como Carta de Banjul) foi adotada pela Assembléia dos representantes da OUA, em 27 de junho de 1981, em Nairóbi, Quênia, e entrou em vigor somente em 21 de outubro de 1996 com o objetivo de priorizar os direitos dos povos.

Os obstáculos que enfrenta o sistema africano estão relacionados a elementos de ordem histórica, estrutural e política, assim como características próprias que o diferencia de padrões ocidentais de proteção de direitos. O sistema africano deriva de um sentido comunitário distinto do ocidental e que de certa forma se mantém desde o pré-colonialismo. ${ }^{10}$ Esse sentido particular foi considerado quando da elaboração dos documentos regionais, conceitos que ao serem consagrados promoveram o repensar na matéria influenciando a forma de interpretar os direitos humanos em outros sistemas de proteção.

Os aparentes antagonismos indivíduo e povo, direitos individuais e direitos coletivos e a forte preocupação com os direitos sociais, econômicos e culturais são características

sem deixar de fazer uma análise estrita da prova e das alegações das partes e sem restringir as considerações de fato e de direito pertinentes.

${ }^{10}$ Contexto em que o individuo era avaliado pelo que exercia na comunidade, em grupo e as decisões políticas normalmente eram tomadas por meio de consenso comunitário, o que afetavadiretamente o conceito de direitos, estando esses correlacionados a deveres. A propriedade tinha um sentido comum, a família compreendia também a vila ou a tribo e as fronteiras eram algo móvel, indefinido, conceitos que se mantiveram e que ainda hoje influenciam a tomada de decisão - seja política ou jurídica - das sociedades africanas. 
próprias do sistema africano e revelam a necessidade de existência de um sistema sólido e capaz de assegurar direitos, mesmo sendo incapaz de superar as heranças do passado de colonização.

Um sistema de proteção de direitos humanos de corte ocidental não seria o mais adequado para atender a complexa formação cultural e política da África, nem mesmo atenderia às necessidades mais urgentes desta que é a região mais sensível do planeta em matéria de violação de direitos humanos. Contudo, e principalmente porque ressalva os antagonismos mencionados, o sistema africano profundamente influenciado pelo sistema das Nações Unidas, passa a ser um importante instrumento de garantias mínimas, necessárias também quando, como veremos adiante, o direito humanitário necessitar do apoio normativo dos direitos humanos estabelecidos em documentos de proteção contra arbitrariedades do aparato estatal.

O sistema africano costuma receber críticas em razão dos dispositivos contidos na Carta Africana serem de redação vaga e, como tais, desprovidos de força executória. Porém, eis que, ao mesmo tempo, está-se diante de um incomparável e excepcional sistema internacional de proteção de direitos humanos que, do ponto de vista normativo, contempla com êxito a interdependência dos direitos humanos. O sistema africano, por essa razão, representa um avanço desejado como ideal pelos doutrinadores de direitos humanos, ao conformar em um mesmo instrumento normativo todos os direitos de modo igual e coerente. ${ }^{11}$

11 VOS, Pierre de. Um nouveau commencement? L'application des droits sociaux, économiques et culturels de la charte africaine sur les droits des humains et des peuples. En Les droits sociaux fondamentaux à l'âge de la mondialisation. Aix-en-Provence: Presses Universitaires, 2005, pp.33-34.
O mais significativo é que a formulação desses direitos não está vinculada a obrigações de efetividade por parte do Estado, conforme tradicionalmente ocorre nos sistemas da ONU e nos regionais americano e europeu. Os documentos internacionais de proteção de direitos econômicos, sociais e culturais do sistema universal e dos sistemas europeu e americano declaram o princípio da progressividade e determinam como horizonte de cumprimento a plena efetividade de direitos, convocando para tal todos os meios necessários, inclusive cooperação e assistência internacional.

\section{Organização das Nações Unidas (ONU):}

Pacto Internacional dos Direitos Econômicos, Sociais e Culturais (1966)

Art. $2^{\circ}$ : §1: Cada Estado Membro no presente Pacto compromete-se a adotar medidas, tanto por esforço próprio como pela assistência e cooperação internacionais, principalmente nos planos econômico e técnico, até o máximo de seus recursos disponíveis, que visem a assegurar, progressivamente, por todos os meios apropriados, o pleno exercício dos direitos reconhecidos no presente Pacto, incluindo, em particular, a adoção de medidas legislativas. (grifo nosso).

\section{Organização dos Estados Americanos (OEA):}

Convenção Americana de Direitos Humanos ou "Pacto de San José da Costa Rica" (1969) Capítulo III, Artigo 26: Desenvolvimento progressivo. Os Estados Membros comprometem-se a adotar as providências, tanto no âmbito interno, como mediante cooperação internacional, especialmente econômica e técnica, a fim de conseguir progressivamente a plena efetividade dos direitos que decorrem das normas econômicas, sociais e sobre educação, ciência e cultura, constantes da Carta da Organização dos Estados Americanos, reformada pelo Protocolo de Buenos Aires, na medida dos recursos disponíveis, por via legislativa ou por outros meios apropriados. (grifo nosso). 
Protocolo Adicional à Convenção Interamericana Sobre Direitos Humanos em Matéria de Direitos Econômicos, Sociais e Culturais, "Protocolo de San Salvador" (1988)

Artigo $1^{\circ}$ : Obrigação de adotar medidas. Os Estados Membros neste Protocolo Adicional à Convenção Americana sobre Direitos Humanos comprometem-se a adotar as medidas necessárias, tanto de ordem interna como por meio da cooperação entre os Estados, especialmente econômica e técnica, até o máximo dos recursos disponíveis e levando em conta seu grau de desenvolvimento, a fim de conseguir, progressivamente e de acordo com a legislação interna, a plena efetividade dos direitos reconhecidos neste Protocolo (grifo nosso).

A obrigação de progressividade presente nos artigos supracitados, além de determinação de método, é também mandamento de não retrocesso, a proibição de que sejam adotadas medidas que agravem, derroguem ou reduzam a proteção aos direitos econômicos, sociais e culturais conquistados ou efetivados.

No entanto, a redação dos artigos submete a efetividade até o limite dos recursos disponíveis e leva em consideração o grau de desenvolvimento do Estado. A previsão, que como tal pode ensejar escusa por descumprimento de obrigações dessa natureza, explica-se pela existência de limites orçamentários dos Estados, os quais variam de acordo com o grau de desenvolvimento do país e, por correlação, explica-se tendo em vista a expectativa de compromisso dos Estados e do princípio da reserva legal, da não interferência em assuntos internos quando o descumprimento poderia questionar políticas públicas e de planejamento estrutural ou até um julgamento político do Estado.

Os grupos de trabalho encarregados em definir os termos adequados na redação dos pactos tiveram muita dificuldade para aprovar o conteúdo compatível com as legislações nacionais. As diferenças de concepção de sociedade, próprias do período da Guerra Fria, também influenciaram a redação de distintos pactos no âmbito das Nações Unidas e a instauração cautelosa de mecanismos para a verificação do cumprimento dos direitos econômicos, sociais e culturais. ${ }^{12}$

No caso africano, essa ausência, em especial a ausência da progressividade vinculada à quantidade de recursos existentes dentro do Estado, evidencia a vontade deliberada de não isolar esses direitos dos demais e vincular a responsabilidade imediata e inescusável do Estado, seja o agir que vinculam prestações negativas ou positivas por parte do ente estatal. No entanto, na prática a Comissão Africana já admitiu que a intensidade da aplicabilidade imediata é variável de acordo com o tipo de direito em questão e com o contexto de aplicação.

Carta Africana dos Direitos Humanos e dos Povos, Carta de Banjul (1981)

Preâmbulo: Convencidos de que, para o futuro, é essencial dedicar uma particular atenção ao direito ao desenvolvimento; que os direitos civis e políticos são indissociáveis dos direitos econômicos, sociais e culturais, tanto na sua concepção como na sua universalidade, e que

12 A existência de dois Pactos Internacionais separando os direitos em "gerações" foi uma opção possível à época, pois um único documento contemplando a unidade dos direitos seria rechaçado por países de corte socialista e capitalista. A mais importante distinção que se estabeleceu em 1966 com a aprovação dos Pactos e com a criação do Comitê que estabeleceu procedimentos para a investigação de direitos civis e políticos, foi no tocante ao sistema de análise internacional dos diferentes grupos de direitos. O procedimento estabelecido pelo Comitê é muito mais eficiente que o sistema de relatórios e informes contemplados para os direitos econômicos, sociais e culturais, os quais não prevêem mecanismos de comunicação da violação. 
a satisfação dos direitos econômicos, sociais e culturais garante o gozo dos direitos civis e políticos;

Capítulo I - Dos Direitos Humanos e dos Povos: Artigo $1^{\circ}$ Os Estados membros da Organização da Unidade Africana, Partes na presente Carta, reconhecem os direitos, deveres e liberdades enunciados nesta Carta e comprometem-se a adotar medidas legislativas ou outras para os aplicar. (grifo nosso).

A Comissão Africana dos Direitos do Homem e dos Povos, criada pela Carta, constitui um órgão técnico independente, composto por 14 membros escolhidos por suas qualidades pessoais, encarregado da promoção e proteção dos direitos do homem.

A Comissão recebe dois tipos de comunicação. As comunicações provenientes de Estados-partes são precedidas de um contato formal entre os Estados antes da participação do órgão administrativo. Em contato bilateral, a comunicação escrita deve ser encaminhada ao Secretário-Geral da OUA e os Estados em disputa têm o prazo de três meses para chegar a um acordo pacífico. Só então, com a negativa da solução amistosa, o caso é encaminhado à Comissão que, após analisar a admissibilidade (esgotamento dos recursos internos), procede à análise de mérito e exerce papel de conciliadora na tentativa de solução amistosa. Frustradas as tentativas de acordo, a Comissão elabora relatório com a descrição dos fatos e as conclusões e envia aos Estados interessados e à OUA (Conferência dos Chefes de Estado e de Governo).

O segundo tipo de comunicação pode ser encaminhado por indivíduos, grupos de indivíduos ou organizações não-governamentais que sejam ou não consideradas vítimas de violação. Uma vez admitidas (superadas as condições de admissibilidade arroladas no artigo 56), o caso segue processo similar ao estabelecido em procedimento de outros instrumentos regionais. Caso a Comissão avalie que se tratam de violações graves ou maciças contra os direitos humanos e dos povos, a Conferência dos Chefes de Estado e de Governo será acionada para que seja realizado estudo aprofundado e que resulte em relatório e recomendações no sentido de cessar as causas de violações.

Os procedimentos perante a Comissão ocorrem na forma confidencial e o relatório só será publicado pelo Presidente da Comissão Africana se a Conferência dos Chefes de Estado e de Governo assim decidir. Resulta daí a principal limitação do sistema africano, pois nem mesmo a sanção de dotar de publicidade as violações ocorridas em um determinado Estado, sanção possível pela atuação da Comissão, nem mesmo esse recurso é eficaz, já que recebe restrições no âmbito da Conferência dos Chefes de Estado e de Governoe, portanto, recai na conveniência política de se constatar publicamente a responsabilidade de um Estado.

A Carta Africana estabelece que da denúncia constará uma lista de comunicações que será transmitida aos membros da Comissão. No caso de violações graves e massivas de direitos humanos e dos povos, estudos aprofundados podem ser elaborados, de acordo com o regulamento interno da Comissão, mas o relatório final se reporta à Organização da União Africana, e não diretamente ao Estado, representando outra limitação comparativa aos demais sistemas existentes.

Conforme define a Comissão, a Carta Africana de Direitos Humanos e dos Povos é um documento de características excepcionais e que contempla os direitos coletivos, os 
direitos relacionados ao desenvolvimento e os direitos econômicos e sociais que são essenciais ao continente africano, enfrentados à luz do contexto continental. No entanto, muitos obstáculos ainda se interpõem ao bom funcionamento do sistema, obstáculos que são condicionados pela realidade do imenso continente.

A criação e entrada em vigor da Corte Africana de Direitos Humanos é um reforço extraordinário na institucionalização do sistema africano. As decisões da Corte possuem força de coisa julgada definitiva e obrigatória para os Estados que aceitaram sua competência. A execução da sentença fica a cargo do Comitê de Ministros da Organização da União Africana.

Os avanços e principalmente as dificuldades de operacionalidade dos sistemas regionais estão relacionados ao contexto espacial de aplicação. A Europa se encontra em um momento de construção e consolidação de sua integração econômica, trazendo conseqüentemente a necessidade de adaptação política e social para um modelo construído para atender objetivos prioritariamente econômicos. Eis a razão da crise de funcionamento não apenas do sistema do Tribunal Europeu de Direitos Humanos, como mencionado, mas também de legitimidade dos documentos de proteção do indivíduo que agora estão ameaçados diante da necessidade de reajustes dos Estados individualmente e das normas comunitárias.

No caso americano, o continente convive com a permanente tensão do norte hegemônico e pouco colaborativo em matéria de direitos humanos. No caso estadunidense, além de não fazer parte da Convenção Americana e nem reconhecer a competência da Corte, o país representa uma iminente ameaça política e militar diante do continente e de suas contingências.

A África por si só representa o exemplo mais visível da necessidade de normatização e aplicação de normas de direitos humanos. O continente reúne as formas mais cruéis de conflitos armados e mais autoritárias de administração estatal, modelos que destoam dos sistemas contemporâneos de regulação estatal e das chamadas conquistas democráticas. O continente africano permite compreender claramente a necessidade de operação conjunta das normas de proteção internacional da pessoa humana, pois a barbárie dos conflitos não se enquadra em vertentes de violação, já que é absoluta e contempla do mais sutil ao mais denso sentido de existência humana.

\section{VERTENTE DO DIREITO INTERNACIONAL HUMANITÁRIO}

A segunda vertente de proteção internacional dos direitos humanos, o direito internacional humanitário tem origem em circunstâncias distintas às do direito internacional dos direitos humanos e localiza seu objeto de estudo na proteção dos bens direta e indiretamente ameaçados pelos conflitos bélicos e na limitação dos meios e métodos de combate. Tem como principal escopo criar condições de paz e de segurança àqueles seres humanos vulneráveis, que não participam ou que deixaram de participar das hostilidades.

Esse conjunto de tratados e de costumes internacionais remonta às formas antigas de se fazer e de se limitar a guerra, atravessa os tempos resgatando valores e princípios humanitários em cada sociedade e assume, a 
partir do século XIX, um marco regulatório internacional e universal. A primeira convenção internacional sobre a matéria foi a Convenção de Genebra de $1864 .{ }^{13}$ Desde então, inúmeras convenções, pactos e novos costumes vão delinear não apenas as regras do jus in bello, como também do chamado jus post bellum, direito que regula o julgamento dos acusados que cometeram violações das normas humanitárias. ${ }^{14}$

A violação das normas de direito internacional humanitário não supõe a responsabilidade do Estado como agente causador principal. Não obstante, o Estado segue sendo responsável pela consolidação do direito humanitário no âmbito internacional e interno.

${ }^{13}$ Segundo Eulália W.P. de Gabriel o ius in bello, conjunto de normas que regulam a guerra durante seu desenvolvimento, não nasce repentinamente com a Convenção de 1864 , mas por um longo processo que se formou através dos séculos mostra como já no século XVIII havia certo sentimento humanitário, mesmo no período de Luis XV e também com um decreto, já após a revolução, de 25 de maio de 1793 , no qual se destina um artigo aos cuidados de enfermos e feridos. Demonstra, ainda, a importância do Código Lieber, de 1863, para a Guerra de Secessão Americana. PETIT DE GABRIEL, Eulália W. Las exigências de humanidad en el derecho internacional tradicional (1789-1939). Madrid: Tecnos, 2003, p.135-147.

14 Jean Marcel Fernandes explica que "a condenação internacional dos conflitos armados não exclui a aplicação do jus in bello, cuja tradução direito na guerra - em vez de direito da guerra, expressão mais utilizadas na doutrina - representa melhor o significado do conceito. As normas que limitam a violência, nas vertentes de Genebra (proteção de vítimas e bens), Haia (regras de combate) e Nova Iorque (salvaguarda de direitos humanos e limitação do uso de certas armas)" Explica ainda o autor que o jus post bellum, também conhecido como Direito de Roma, tem por objetivo punir as violações ao direito humanitário, como é o caso do Tribunal Penal Internacional. (FERNANDES, Jean Marcel. A promoção da paz pelo direito internacional humanitário. Porto Alegre: Fabris, 2006. p.47-48.
As ações contrárias ao direito humanitário podem ser provenientes de governantes no uso do aparato estatal e também podem ser não governamentais, ações de grupos armados, milícias, grupos não-identificados (conflitos armados internacionais - CAI - e conflitos armados não-internacionais - CANI).

De acordo com Larissa Ramina, os conflitos armados internacionais envolvem um aspecto militar e um aspecto internacional, sendo que seu conceito é mais amplo do que o conceito clássico de guerra. A partir de 1949 o conceito passou a contemplar as lutas por independência, casos de ocupação estrangeira e lutas contra regimes racistas a partir da aplicação do princípio da autodeterminação. ${ }^{15}$

Os conflitos armados não internacionais inicialmente não eram tratados pelo direito

15 De acordo com Larissa Ramina, na Conferência Diplomática de 1974 a 1977, ocasião em que foram adotados os dois Protocolos Adicionais às Convenções de Genebra de 1949, ampliou-se a noção de CAI. Em outras palavras, os CAI opõem dois ou mais Estados, abrangem casos de ocupação total ou parcial do território, ainda que sem resistência militar, bem como conflitos armados em que os povos lutam contra a dominação colonial e a ocupação estrangeira e os regimes racistas, no exercício dos povos à autodeterminação consagrada na Carta das Nações Unidas. Em termos de elementos constitutivos, segundo a autora, é possível dizer que um CANI não tem caráter internacional e realiza-se nos limites territoriais de um Estado, quando as forças armadas deste Estado opõem-se às forças armadas ou a grupos armados que não reconhecem a sua autoridade, sendo que estas forças e estes grupos armados devem estar sob o comando de uma autoridade responsável, e devem exercer um domínio sobre uma parte do território desse Estado que lhes permita realizar operações militares contínuas e acordadas, e aplicar as disposições de DIH do PA II. Conferencia CAI e CANI ministrada no $1^{\circ}$ Curso Introdutório ao Ensino e Integração do Direito Internacional Humanitário para Professores dos Meios Acadêmicos do Estado do Paraná, Brasil. Curso promovido pelo Comitê Internacional da Cruz Vermelha (CICV) em parceria com o Programa de Mestrado em Direito da UniBrasil e aconteceu nos dias 16 a 19 de junho, em Curitiba na UniBrasil. 
humanitário por serem considerados assuntos de jurisdição interna e inseridos no âmbito do domínio reservado dos Estados. Atualmente são considerados conflitos que ocorrem no território de um Estado, entre suas forças armadas e forças armadas dissidentes, ou grupos organizados sob o comando de um responsável, que exerçam sobre uma parte de seu território um controle que lhes permita desenvolver operações militares contínuas. ${ }^{16}$

Comparando com a vertente anterior, os indivíduos não possuem direito de petição individual no direito internacional humanitário. Os indivíduos, ao contrário, podem figurar como sujeitos passivos de processo que envolva violação de direito humanitário, podendo ser condenado por crime de genocídio, crimes contra a humanidade, crimes de agressão, crimes de guerra; delitos definidos pelo Estatuto de Roma que instituiu o Tribunal Penal Internacional, independente de hierarquia governamental ou militar. Esse novo estatuto consolida a posição do indivíduo como sujeito passivo de direito internacional.

Como objetivo de fundo, o direito internacional humanitário procura reprimir a guerra por intermédio da proibição mesma (jus contra bellum), ou das formas de limitação das hostilidades (jus in bello), coibição e reparação a partir do julgamento dos acusados (jus post bellum). ${ }^{17}$

Quando as normas do direito internacional humanitário destinam-se a proteger as vítimas em combate, a doutrina normalmente

${ }^{16}$ Definição proveniente do artigo 1 do Protocolo II Adicionais às Convenções de Genebra de 1949.

17 Ver FERNANDES, Jean Marcel. A promoção da paz pelo direito internacional humanitário. Porto Alegre: Fabris, 2006. considera como parte do chamado Direito de Genebra, cujos principais documentos são: em 1864 a Convenção de Genebra; em 1906 a revisão e desenvolvimento da Convenção de Genebra de 1964; em 1925 o Protocolo de Genebra relativo à Proibição do Emprego na Guerra de Gases Asfixiantes, Tóxicos ou Similares e Meios Bacteriológicos; em 1929 a revisão e desenvolvimento da Convenção de Genebra de 1929 e a Convenção de Genebra relativa ao Tratamento dos Prisioneiros de Guerra; em 1949 as Convenções de Genebra, a I Convenção para Melhorar a Situação dos Feridos e Doentes das Forças Armadas em Campanha, a II Convenção para Melhorar a Situação dos Feridos, Doentes e Náufragos das Forças Armadas do Mar e a III Convenção relativa ao Tratamento dos Prisioneiros de Guerra; em 1977, o Protocolo Adicional às Convenções de Genebra de 1949, o I Protocolo relativo à Proteção das Vítimas em Conflitos Armados Internacionais e o II Protocolo relativo à Proteção das Vítimas em Conflitos Armados Não Internacionais.

Quando normas do direito internacional humanitário destinam-se a limitar os meios e métodos de combate em conflitos armados, a doutrina considera como parte do chamado Direito de Haia, cujos principais documentos são: em 1868 a Declaração de São Petesburgo; em 1899 a Primeira Conferência Internacional da Paz da Haia, a II Convenção sobre as Leis e Costumes da Guerra Terrestre e a III Convenção para Aplicar à Guerra Marítima os Princípios da Convenção de Genebra de 1864; em 1907 a Segunda Conferência Internacional da Paz da Haia, a IV Convenção sobre Leis e Costumes da Guerra Terrestre e a X Convenção para Aplicar à Guerra 
Marítima os Princípios da Convenção de Genebra; em 1954 a Convenção de Haia para a Proteção de Bens Culturais em Caso de Conflito Armado.

Ao conjunto de normas de direito internacional humanitário proveniente do sistema das Nações Unidas e, portanto, atualizadas a partir dos consensos do pós Segunda Guerra, a doutrina considera como parte do chamado Direito de Nova Iorque, cujos principais documentos são: em 1969 a Resolução 2603 A (XXIX), sobre a condenação do uso de armas químicas e biológicas; em 1970 a Resolução 2675 (XXV), sobre a proteção de populações civis durante conflitos armados; em 1972 a Convenção sobre a Proibição de Armas Biológicas (CAB) e resolução 2936 (XXVII) sobre a condenação do uso da força e de armas nucleares; em 1973 a Resolução 3103 (XXVIII), sobre o status jurídico dos combatentes que lutam contra a dominação colonial e estrangeira e regimes racistas; em 1974 a Declaração sobre a Proteção das Mulheres e Crianças em Períodos de Urgência e de Conflito Armado; em 1976 a Convenção sobre a Proibição do Uso de Técnicas de Modificação Ambiental para Fins Militares ou Quaisquer Outros Fins Hostis; em 1974 a 1977 a Conferência Diplomática sobre a Reafirmação e o Desenvolvimento do Direito Internacional Humanitário Aplicável aos Conflitos Armados e seus três Protocolos Adicionais: Protocolo Adicional às Convenções de Genebra de 12 de Agosto de 1949 relativo à proteção das vítimas de conflitos armados internacionais (Protocolo I), Protocolo Adicional às Convenções de Genebra de 12 de Agosto de 1949 relativo à proteção das Vítimas de conflitos armados não-internacionais
(Protocolo II) e Protocolo Adicional às Convenções de Genebra de 12 de Agosto de 1949 relativo a aprovação de um Emblema Distintivo Adicional da Cruz Vermelha e do Crescente Vermelho. (Protocolo III).

Como quarta e última categoria, regras de direito internacional humanitário destinadas à responsabilização internacional do indivíduo, a doutrina considera como parte do chamado "Direito de Roma", em alusão ao Tratado de Roma que deu origem ao Tribunal Penal Internacional (TPI). A instauração do TPI é uma verdadeira revolução na forma de responsabilização internacional por se tratar de jurisdição permanente, com regulamento próprio e capaz de atuar com autonomia e supranacionalidade em benefício comum e sem ofender a soberania dos Estados que aceitem sua jurisdição. Os principais documentos do Direito de Roma são: em 1946 a Resolução 95 sobre princípios do DI reconhecidos pelo Estatuto do Tribunal de Nurembergue; em 1948 a Convenção para a Prevenção e Repressão do Crime de Genocídio; em 1968 a Convenção sobre a Imprescritibilidade dos Crimes de Guerra e dos Crimes Contra a Humanidade; em 1973 a resolução 3074 (XXVIII) sobre a Cooperação Internacional no Tratamento de Criminosos de Guerra; em 1993 o Estatuto do Tribunal Internacional para a ex-Iugoslávia; em 1994 o Estatuto do Tribunal Internacional para Ruanda; em 1998 (17 de julho) foi adotado o Estatuto de Roma que institui o Tribunal Penal Internacional.

O trabalho de promoção e de difusão do direito internacional humanitário conta com a atuação precípua do Comitê Internacional da Cruz Vermelha (CICV), organização humanitária com sede em Genebra e com 
mandato da comunidade internacional para servir de guardião desse direito. ${ }^{18}$ Atuando em diálogo com os Estados, com organismos internacionais e, especialmente, atuando na interlocução das partes em conflito, a Cruz Vermelha obtém resultados essenciais à promoção, difusão e garantia do direito humanitário, logrando resultados importantes, diminuindo os danos e o sofrimento de seres humanos em situações de conflito armado.

O Movimento Internacional da Cruz Vermelha e do Crescente Vermelho ${ }^{19}$ adota sete princípios fundamentais, sendo o primeiro deles o princípio da humanidade, valor que instrui e inaugura o movimento. Outros princípios visam assegurar livre e plena atuação ao Movimento e aos seus agentes, especialmente garantindo salvoconduto nos locais dos conflitos. Este é o caso dos princípios da neutralidade, abstenção de participar das controvérsias políticas, raciais, religiosas ou ideológicas, da imparcialidade, não fazendo nenhuma distinção de nacionalidade, raça, religião, condição social ou filiação política, e também o princípio da

${ }^{18}$ O Comitê Internacional da Cruz Vermelha tem status de pessoa jurídica internacional. Segundo César Amorin Krieger "Sua natureza jurídica é derivada das quatro Convenções de Genebra de 1949 e dos Protocolo Adicionais de 8 de junho de 1977, que lhe conferem credenciamento com fins de laborar de forma neutra em conflitos armados internos ou internacionais." KRIEGER, César Amorin. Direito Internacional Humanitário: o precedente do Comitê Internacional da Cruz Vermelha e o Tribunal Penal Internacional. Curitiba: Juruá, 2005, p.104.

19 Segundo César Amorin Krieger "O Comitê Internacional da Cruz Vermelha deu origem ao Movimento Internacional da Cruz Vermelha e do Crescente Vermelho, sendo constituído pelo próprio CICV, pela Federação das Sociedades da Cruz Vermelha e do Crescente Vermelho." KRIEGER, César Amorin. Op.cit, p.113. independência, garantindo ao Movimento atuação livre e independente até mesmo dos poderes públicos, ainda que submetidos às leis de cada Estado. O Movimento empenhase em socorrer voluntariamente - princípio do voluntariado - aos indivíduos na medida de seu sofrimento, dando prioridade aos casos mais urgentes e graves. O princípio da unidade define que só pode haver uma única Sociedade da Cruz Vermelha e do Crescente Vermelho no mesmo país e o Movimento da Cruz Vermelha e do Crescente Vermelho constitui uma organização universal princípio da universalidade - no seio da qual todas as Sociedades têm direitos iguais e o dever de se ajudarem mutuamente. ${ }^{20}$

A atuação do Movimento se dá em muitas frentes. O CICV atua diretamente no conflito, auxiliando no contato entre familiares de desaparecidos, visitando detidos e facilitando a comunicação com seus familiares e governos, fornecendo água, medicamentos e alimentos às vítimas dos conflitos, facilitando o deslocamento de populações para regiões a salvo das hostilidades, atuando diretamente por meio do estabelecimento de hospitais e enfermarias para atendimento dos feridos.

Essa e tantas outras ações fazem do Movimento um agente privilegiado na identificação de situações que demandam a interferência do direito. Amparada pelo direito de iniciativa previsto nos Estatutos, o CICV opera na qualidade de instituição independente, podendo promover qualquer

${ }^{20}$ VALLADARES, Gabriel Pablo. A contribuição do Comitê Internacional da Cruz Vermelha (CICV) aos últimos avanços convencionais do direito internacional humanitário. Em Direito internacional humanitário e a proteção internacional do indivíduo (Proner, C., Guerra, S. Organizadores). Porto Alegre: Fabris, 2008. 
iniciativa humanitária que tenha relação com o seu papel. Nesse sentido, por seu trabalho de campo, o Movimento revela-se potencial criador de costumes jurídicos, fonte de direito humanitário capaz de informar costumes e ajudar a construir o direito internacional.

Também é trabalho do CICV a promoção do direito humanitário realizado por meio de programas de formação, educação e sensibilização. O sentido fundamental desse trabalho é o de dotar os atores-chave das atitudes e comportamentos previstos nos princípios do CICV, garantindo melhores condições de tratamento e maior segurança nas ações humanitárias. São primeiramente considerados como atores-chave os membros das forças armadas, da política e das forças de segurança de um Estado. Também são entendidos como atores-chave os líderes de opinião tanto no plano local como internacional e a própria juventude, considerada em médio e longo prazo.

Todo o trabalho, em amplas frentes, seria pouco efetivo caso o Direito Internacional Humanitário e o CICV não contassem com a participação dos Estados de respeito aos compromissos assumidos em âmbito internacional. O compromisso envolve várias etapas: inicialmente a negociação e os atos de incorporação do tratado à ordem interna (negociação, assinatura, mensagem ao Congresso, aprovação parlamentar, ratificação, promulgação, publicação e registro). Somente a partir dessa etapa é que terá início o período de implementação efetiva, ou seja, de aplicabilidade das normas de direito humanitário, de compatibilização do direito pactuado com as normas de direito interno e da construção de uma ordem pacificadora. ${ }^{21}$

\footnotetext{
${ }^{21}$ FERNANDES, Jean Marcel. Op.cit., p. 96.
}

Esse trabalho só será completo se o Estado efetivamente adotar os princípios e as regras de direito internacional humanitário em sua plenitude, compatibilizando-as com o seu corpo de leis e, ato contínuo, proporcionando os meios de implementação, fazendo prevalecer na sociedade o espírito humanitário. É por esta razão que o direito internacional humanitário, à semelhança do que ocorre com a vertente anterior, depende, sobretudo, do Estado e de seu nível de participação na construção dos objetivos definidos pela comunidade internacional, não apenas na prevenção e limitação do jus in bello, como também na adesão aos instrumentos do jus post bellum.

A cooperação dos Estados implica conduta omissiva, no sentido de deixar de praticar ato lesivo às normas de direito internacional humanitário e conduta ativa, no sentido de coibir práticas desconformes as mesmas normativas, praticadas por grupos ou milícias, entes que sob sua jurisdição venham a praticar atos que caracterizem conflito armado.

$\mathrm{O}$ direito internacional humanitário conquistou um importante instrumento quando foi instituído o Tribunal Penal Internacional. A responsabilidade internacional dos indivíduos por violação do direito humanitário representa a possibilidade de sanção, de reparação, ainda que imperfeita, dos danos causados por conflitos armados. No entanto, alguns Estados seguem resistentes a ratificar o Tratado de Roma, alguns alegando defesa de sua soberania, extensiva aos cidadãos, e entendendo que o julgamento de seus nacionais lesaria interesse próprio.

As controvérsias que abrangiam a adesão à supranacionalidade em matéria penal foram 
superadas a partir da compreensão do Tribunal Penal Internacional como instância supranacional de natureza complementar às jurisdições penais nacionais, conforme definido no Capítulo I do Estatuto de Roma. O princípio da complementaridade desarma muitas críticas que precipitadamente foram direcionadas ao funcionamento da corte penal. O TPI respeita e consagra a soberania dos Estados aos seus respectivos sistemas internos.

Outro ponto que também desarmou argumentos contrários ao TPI foi a compreensão clara da natureza desse tribunal como sendo a de julgar pessoas responsáveis pelos crimes de maior gravidade com alcance internacional, notadamente o crime de genocídio, os crimes contra a humanidade, os crimes de guerra e os crimes de agressão. A compreensão do papel dessa Corte vai além do Estatuto em si e de seus procedimentos processuais, significando o esforço internacional por constituir uma instância permanente, autônoma e dotada de todas as garantias de ordem jurídica tanto para as vítimas quanto para os acusados.

As experiências anteriores de tribunais ad hoc, marcadas por parcialidade, influência política e violação dos princípios da legalidade e da ampla defesa, são suficientes para fazer reconhecer a necessidade de uma instância neutra competente para promover o julgamento dos envolvidos em crimes humanitários de grandes proporções.

A legalidade e a legitimidade do TPI está atualmente assegurada por 104 países que aderiram ao Estatuto de Roma. O Brasil assinou o Estatuto em fevereiro do ano 2000, depositou o instrumento de ratificação no mês de junho de $2002^{22}$ e atualmente procede à regulamentação da Corte por meio de projeto de lei em trâmite. No entanto, muitos países recusam a jurisdição desse tribunal. Os EUA não apenas se recusam como também assinaram acordos bilaterais com 24 nações para que as mesmas não entreguem seus cidadãos ao TPI. ${ }^{23}$ A lamentável postura desse país não pode ser considerada uma exceção diante da proporção assumida pela política externa estadunidense em conflitos armados que desrespeitam as normas de direito humanitário. Os EUA pretendem evitar que a alegação de "legitima defesa preventiva" utilizada na invasão do Iraque seja tipificada como "crime de agressão" e possa gerar responsabilidades derivadas de seus militares e de seus governantes.

\section{VERTENTE DO DIREITO I N T E R N A C I O N A L D O S REFUGIADOS}

A terceira vertente de proteção internacional dos direitos humanos, o direito internacional dos refugiados, apresenta normativa de aplicação própria, mas sua concepção está completamente confundida com as normas que constituem o sistema internacional de proteção dos direitos humanos.

${ }^{22}$ O Decreto n. $^{\circ}$ 4.388/2002 promulgou o Estatuto de Roma do Tribunal Penal Internacional no ordenamento brasileiro. A aceitação de jurisdição do TPI está expressamente definida pela Constituição brasileira no

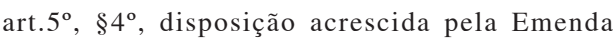
Constitucional 45/2004.

${ }^{23}$ Normalmente os EUA utilizam os acordos bilaterais de natureza econômica - de livre comércio para incluírem a cláusula de não entrega de cidadãos americanos ao TPI, utilizando-se de sua política hegemônica e condicionando o pólo mais fraco a aceitar as condições. 
A situação de refúgio - fuga do perigo e busca de proteção, socorro, amparo - pressupõe o desamparo da situação anterior, o abandono provisório do lar, de uma comunidade, de uma vida organizada em direção ao incerto, levando consigo a expectativa de que sua vida e seus direitos - seja respeitada e protegida.

As origens da conceituação e do reconhecimento da condição de refugiado podem ser buscadas na Grécia antiga, em Roma, passa pelo cristianismo e o acolhimento de pessoas em templos religiosos, remonta o absolutismo real e as relações diplomáticas que então se estabeleciam. Mas é no século XX que o marco jurídico de proteção passa a ser desenhado e adaptado a uma aplicação universal. A Revolução Russa marca as origens de um sistema de repatriação de prisioneiros de guerra e cria o Alto Comissionado para os Refugiados Russos em 1921. Um exemplo desse importante momento foi a criação do Passaporte Nansen, documento que permitiu a emigração de milhares de russos após a revolução de $1917 .{ }^{24}$

Com o surgimento de novos sujeitos de refúgio: judeus não-arianos e opositores ao regime do nacional socialismo alemão, a Liga das Nações passou a administrar os problemas de refúgio na Europa e em outros continentes. A configuração do que existe atualmente desde 1951 com a Conferência das Nações Unidas de Plenipotenciários sobre o Estatuto dos Refugiados e Apátridas, ${ }^{25}$ e após, em

${ }^{24}$ Ao criador do passaporte Fridtjof Nansen foi atribuído em 1938 o Prêmio Nobel da Paz.

25 Ver Antônio Augusto Cançado Trindade, Gérard Peytrignet e Jaime Ruiz de Santiago. As Três vertentes da proteção internacional dos Direitos da Pessoa Humana, San José da Costa Rica: IIDH, Comitê Internacional da Cruz Vermelha, Alto Comissariado das Nações Unidas para os Refugiados, 1996.
1967, com o estabelecimento do Protocolo sobre o Estatuto dos Refugiados, documento que ampliou o alcance da definição de refugiado - é resultado dos acertos do entre e do pós-Guerras e da necessidade de os Aliados repatriarem as vítimas do conflito.

Mesmo com o Estatuto dos Refugiados de 1951, a definição somente ganhou contornos universais em 1967, quando a proteção passou a ser ampla e irrestrita, atendendo a milhares de pessoas em situação de refúgio.

De acordo com o Estatuto dos Refugiados de 1951 , no artigo $6^{\circ}$, item A.II, considera-se refugiado

a pessoa que, como resultado de acontecimentos ocorridos antes de $1^{\circ}$ de janeiro de 1951, e devido a fundados temores de ser perseguido por motivos de raça, religião e nacionalidade ou opinião política, se encontre fora do país de sua nacionalidade e não possa ou, em razão de tais temores ou razões que não sejam de mera conveniência pessoal, não queira receber a proteção desse país, ou que, por carecer de nacionalidade e estar fora do país onde antes possuía sua residência habitual não possa ou, por causa de tais temores ou de razões que não sejam de mera conveniência pessoal, não queira regressar a ele.

O Protocolo sobre o Estatuto dos Refugiados de 1967 amplia o conceito fornecido pela Convenção de 1951, estabelecendo em seu artigo $1^{\circ}$, item II, que:

... 2. Para os fins do presente Protocolo, o termo "refugiados", salvo no que diz respeito à aplicação do $\S 3^{\circ}$ do presente artigo, significa qualquer pessoa que se enquadre na definição dada no artigo primeiro da Convenção, como se a palavras 'em decorrência dos acontecimentos ocorridos antes de $1^{\circ}$ de janeiro de 1951' e... 'e as palavras'... como consequiência de tais acontecimentos não figurassem da Seção A do artigo primeiro. 
A constituição do estado de refúgio está sobremaneira relacionada às violações de direitos civis, processos discriminatórios que sejam lesivos à pessoa, limitações do direito à vida, limitações às liberdades de expressão de culto, liberdades políticas, discriminação racial, cultural, de nacionalidade ou etnia, todas violações que são comuns ao direito internacional dos refugiados e ao direito internacional dos direitos humanos.

O perseguidor pode ser autoridade do próprio país ou de setores da população que não respeitem as normas vigentes, variando em razão de se tratar de conflito armado internacional ou conflito armado não internacional. Também, no caso de existir omissão por parte das autoridades que guardam dever de proteção, pode haver caracterização de perseguição e ensejar o refúgio.

A declaração de refugiado precisa ser realizada levando em conta o caso concreto, a análise individual, já que normalmente se configura a partir da mescla de fatores objetivos e subjetivos. O benefício da dúvida protege a alegação de refúgio - princípio do in dubio pro refugiado - embora não haja dispensa de justificativa.

Outros princípios garantem proteção e estabilidade à condição de refugiado, sem os quais o esforço em reconhecer e proteger o status de fragilidade em que se encontra a pessoa em refúgio seria praticamente anulado. O mais importante é o princípio da não devolução ou princípio da non-refoulement, consagrado no artigo 33 da Convenção de 1951. Nenhum dos Estados Contratantes expulsará ou rechaçará, de forma alguma, um refugiado para as fronteiras dos territórios em que sua vida ou liberdade seja ameaçada em decorrência da sua raça, religião, nacionalidade, grupo social a que pertença ou opiniões políticas. ${ }^{26}$

Outro princípio recomendado pelo Estatuto de 1951 trata da manutenção da unidade familiar do refugiado, e, em especial, a proteção dos menores de idade, entendendo, como o faz a Declaração Universal dos Direitos Humanos de 1948, que a família é elemento natural e fundamental da sociedade e tem direito à proteção da sociedade e do Estado.

O Estatuto de 1951 dispõe sobre outras garantias de manutenção regular da vida do refugiado no país de refúgio, devendo o Estado observar o critério do tratamento mais favorável possivel e em igualdade de condições aos nacionais em matéria de moradia, trabalho e emprego remunerado, exercício profissional, educação, assistência pública, garantia das liberdades, acesso às instancias administrativas para fins de regularização de identidades e documentos de viagem, despesas fiscais e transferências de bens. Além da proibição da expulsão, exceto com causa justificada, ${ }^{27} \mathrm{o}$ Estado ainda deve promover os processos de naturalização nos casos em que seja demandado.

${ }^{26} \mathrm{O}$ artigo 22, VIII, da Declaração Americana dos Direitos Humanos também o consagra. $\mathrm{O}$ artigo $3^{\circ}$ da Convenção das Nações Unidas contra a tortura e outros tratamentos e penas cruéis, desumanas e degradantes estipula que: "Nenhum Estado Parte procederá à expulsão, devolução ou extradição de uma pessoa a outro Estado quando houver fundadas razões para crer que estaria em perigo de ser submetida à tortura."

27 De acordo com o artigo 32 do Estatuto de 1951, os Estados Contratantes não expulsarão um refugiado que esteja regularmente no seu território, senão por motivos de segurança nacional ou de ordem pública. A expulsão desse refugiado somente ocorrerá em conseqüência de decisão judicial proferida em processo legal. 
Os deveres dispostos aos Estados pela Convenção e pelo Protocolo Relativo ao Estatuto dos Refugiados demonstram inequívoca coincidência de propósitos entre as vertentes de direitos humanos, mais especificamente entre o direito dos refugiados e as normas de proteção internacional dos direitos humanos (e cumprimento dos direitos fundamentais dispostos normalmente nas cartas constitucionais).

Como bem identifica Cançado Trindade, "em nada surpreende que muitos dos direitos humanos universalmente consagrados se apliquem diretamente aos refugiados (e.g., Declaração Universal dos Direitos Humanos, artigos 9 e 13-15; Pacto de Direitos Civis e Políticos, artigo 12). Do mesmo modo, preceitos do direito dos refugiados aplicam-se também no domínio dos direitos humanos, como é o caso do princípio da não-devolução (non-refoulement). ${ }^{28}$

A Declaração Universal dos Direitos Humanos dispõe que em caso de perseguição, toda pessoa tem direito a buscar asilo e desfrutar do mesmo em qualquer país, bem como assegura o direito a uma nacionalidade. $\mathrm{O}$ direito internacional humanitário faz

${ }^{28}$ Ver texto "As três vertentes da proteção internacional dos direitos da pessoa humana. Direitos Humanos, Direito Humanitário, Direito dos Refugiados", apresentado por Antônio Augusto Cançado Trindade, Gérard Peytrignet, Jaime Ruiz De Santiago e disponível em http://www.icrc.org (consulta em 13 de outubro de 2008). De acordo com os autores, o CICV, ao dedicar-se à proteção e assistência das vítimas de conflitos armados, também se ocupou de refugiados e pessoas deslocadas. A partir da criação do ACNUR, passou o CICV a exercer um papel complementar ao daquele. O CICV tem prestado apoio ao ACNUR desde seus primeiros anos, e tal cooperação tem-se intensificado com o passar do tempo em relação a novas e sucessivas crises em diferentes partes do mundo. menção expressa aos refugiados, deslocados internos e apátridas no IV Convênio de Genebra, de 1949, relativo à proteção aos civis em tempo de guerra. ${ }^{29}$

Alem da convergência no plano normativo e hermenêutico, a principal aproximação ocorre no campo operacional a partir do reconhecimento progressivo que o problema dos refugiados não será resolvido na etapa do refúgio, mas abarca também etapas anteriores, prevenção para que não ocorram especialmente situações de refúgio em massa, e posteriores, a busca de soluções duradouras, a possibilidade de repatriação voluntária, de integração local e de reassentamento, a garantia dos direitos humanos em igualdade de condições aos nacionais do Estado que acolhe o refugiado.

${ }^{29}$ Ver SAADEH, Cyro; EGUCHI, Monica M. Convenção relativa ao estatuto dos refugiados Protocolo sobre o estatuto dos refugiados. Disponível em http://www.pge.sp.gov.br. Acesso em 13 de outubro de 2008. De acordo com os autores, outros instrumentos internacionais também tratam da matéria: a Convenção de 1954 sobre o Estatuto dos Apátridas descreve o conceito de apátrida, ou seja, aquela pessoa que não é considerada como nacional por nenhum Estado, prescrevendo normas de tratamento aos mesmos. A Convenção de 1961 para reduzir os casos de apátridas especifica que não se privará nenhuma pessoa ou grupo de pessoas, por motivos raciais, étnicos, religiosos e políticos, de nacionalidade.A Declaração das Nações Unidas sobre o Asilo Territorial, de 1967, estabelece uma série de princípios fundamentais, como o da não devolução, o direito de sair, retornar e permanecer em qualquer país, inclusive o próprio, e o direito de gozar do direito de asilo, e que o asilo não pode ser considerado inamistoso por nenhum outro Estado, posto que é ato pacífico e humanitário. Na América Latina, o problema do asilo territorial e diplomático tem sido tratado em instrumentos regionais, como o Tratado sobre Direito Penal Internacional (Montevidéo, 1889), o Acordo sobre Extradição (Caracas, 1911), Convenção sobre Asilo (Havana, 1928), Convenção sobre Asilo Político (Montevidéo, 1933), Convenção sobre Asilo Diplomático (Caracas, 1954) e Convenção sobre Asilo Territorial (Caracas, 1954). 
Essas modificações ocorrem a partir das chamadas "Conclusões sobre a Proteção Internacional dos Refugiados" aprovadas pelo Comitê Executivo do Programa do ACNUR e representam um importante passo relativo à complementaridade das vertentes de proteção. ${ }^{30}$

\section{CONCLUSÃO}

A complementaridade, embora amplamente reconhecida pela doutrina que trata da proteção internacional da pessoa humana, ainda enfrenta o desafio da articulação teórica e principalmente prática necessária para garantir ao indivíduo a máxima proteção realizável a partir do apoio mútuo das vertentes estudadas.

\section{As vertentes são complementares} efetivamente porque suas regras são distintas e podem ser aplicadas em alternância ou superposição, substantiva ou processual, de

${ }^{30}$ Ver Antônio Augusto Cançado Trindade, Gérard Peytrignet, Jaime Ruiz De Santiago, op. cit. De acordo com os autores, "Sempre à luz das necessidades de proteção, a dimensão dos direitos humanos tem igual incidência nas etapas "anterior" de prevenção e "posterior" de solução duradoura. Os direitos humanos revestem-se de importância na etapa "prévia" precisamente para assegurar que se consiga o refúgio. A prevenção compreende distintos elementos, a começar pela necessária previsão de situações que possam gerar fluxos de refugiados. O passo seguinte é o que hoje se conhece como alerta antecipado ou imediato (earlyuvrning). (...) Os direitos humanos assumem igual importância na etapa "posterior" de solução duradoura, a qual também requer atenção à situação global dos direitos humanos no país de origem. Com a falta de vigência destes no momento da repatriação ou retorno dos refugiados ao país de origem, criam-se condições para novos êxodos e fluxos de refugiados, os quais voltam a sair de seu país de origem em um círculo vicioso. Deste modo, nesta concepção ampliada de proteção, os direitos humanos se fazem presentes, necessária e invariavelmente, nas três etapas, ou seja, as de prevenção, de refúgio e de solução duradoura". acordo com a situação que se apresente. ${ }^{31}$

Não apenas os propósitos são os mesmos - a proteção do ser humano em todas e quaisquer circunstâncias - mas também a substância da qual procedem é feita da mesma natureza. A partir da compreensão dos “direitos irrevogáveis", dos quais derivam os princípios de proteção comum às três vertentes, torna-se flagrante a preocupação com a proteção da pessoa humana em toda e qualquer circunstância: a inviolabilidade da pessoa humana, o respeito à vida (compreendendo o respeito à integridade física, mental e aos atributos da personalidade), o princípio da não-discriminação, a garantia aos direitos humanos fundamentais em quaisquer circunstâncias, o princípio da segurança pessoal e a proibição da tortura, tratamento cruel ou degradante, proibição da detenção ou prisão arbitrária e respeito ao devido processo legal.

Como bem identifica Cançado Trindade, a complementaridade no plano hermenêutico implica o reconhecimento do caráter especial dos tratados de proteção dos direitos da pessoa humana, um status distinto ou especial quando comparados a outros tratados multilaterais gerais. Esse reconhecimento acarreta conseqüências na aplicação do princípio da reciprocidade, que nesse caso é excetuado em razão da prevalência da ordre public das normas de proteção da pessoa humana. Conforme atesta o artigo $60 \mathrm{da}$ Convenção de Viena, o próprio direito dos tratados descarta o princípio da reciprocidade na implementação de tratado de proteção

31 TRINDADE, A.A. Cançado. Tratado de Direito Internacional dos Direitos Humanos, volumes I, II e III. Editora Sérgio Antonio Fabris. 2003. 
internacional dos direitos humanos e de direito internacional humanitário.

As características especiais dessas normas também ensejam, como amplamente trabalhado pela doutrina, a observância do princípio erga omnes, pois representam obrigações incondicionais, exigíveis independentemente da participação do Estado em um determinado conflito, e cujo integral cumprimento interessa à comunidade internacional como um todo.

O Estado não pode eximir-se de responsabilidade uma vez que participa do ambiente internacional e está obrigado a cooperar para a manutenção da paz e da segurança coletiva. A obrigação nasce de um interesse jurídico comum, interesse coletivo de proteção da pessoa humana, propósito amplamente manifestado em declarações e pactos internacionais e que compele os Estados a respeitar os compromissos assumidos.

Para além dos Estados, é preciso reconhecer o papel fundamental exercido pela sociedade civil internacional, em alguns casos atuando praticamente como organizações internacionais, como é o exemplo do Comitê Internacional da Cruz Vermelha (CICV), ${ }^{32}$ na defesa do direito humanitário e, reconhecendo a complementaridade, procurando atender, dentro das possibilidades de seus estatutos e mandatos, às demais vertentes de proteção da

32 Organização humanitária com sede em Genebra e com mandato da comunidade internacional para servir de guardião desse direito. Atuando em diálogo com os Estados, com organismos internacionais e, especialmente, atuando na interlocução das partes em conflito, a Cruz Vermelha obtém resultados essenciais à promoção, difusão e garantia do direito humanitário, efetivamente diminuindo os danos e o sofrimento de seres humanos em situações de conflito armado. pessoa humana violadas em situação de conflito armado.

$\mathrm{O}$ direito internacional dos direitos humanos em âmbito regional e universal expande-se e consolida-se a partir da participação crescente e atuante das organizações nãogovernamentais aliada, como é imprescindível reconhecer, a uma gestão preocupada e ativa dos órgãos supranacionais de proteção dos direitos humanos.

No caso dos refugiados, centenas de organizações não-governamentais trabalham na reivindicação dos direitos concernentes à situação de refúgio, incluindo não apenas tratamento jurídico como também atendimento às questões materiais, subsídio alimentar, habitacional, psicológico e interlocução com os entes políticos.

A Conferência Mundial de Direitos Humanos realizada em Viena em 1993 representou a consagração da complementaridade por todas as entidades que trabalham com direitos humanos e também pelos Estados. Neste $60^{\circ}$ aniversário da Declaração Universal dos Direitos Humanos (10 de dezembro de 2008), não há quem discorde em compreender o "consenso universal" de 1948 recontextualizado, atualizado a partir das conquistas hermenêuticas dos anos que se seguiram. A Declaração Universal - e principalmente a contradição dos tempos da guerra fria e do estabelecimento de dois Pactos Internacionais separados em 1966 - desloca-se de seu marco histórico, transforma-se e atualiza-se a partir da experimentação prática e da constatação que as garantias apenas no plano formal não apenas são insuficientes como por vezes desviam a atenção e dissipam a energia rumo à efetividade. 


\section{REFERÊNCIAS}

ANDRADE, Isabela Piacentini; KALLAS, Fernanda Araújo. A imunidade dos nacionais americanos à jurisdição do TPI. In: Revista Brasileira de Direito Internacional. Ano I. n. 01. 1 Sem.2005.

BRUNETEAU, Bernard. El siglo de los genocídios: violências, masacres y procesos genocidas desde Armênia a Ruanda. Madrid: Alianza, 2006.

CANÇADO TRINDADE, A.A. Tratado de Direito Internacional dos Direitos Humanos, volumes I, II e III. Editora Sérgio Antonio Fabris. 2003.

CANÇADO TRINDADE, A.A., PEYTRIGNET, G., SANTIAGO, J.R. As Três vertentes da proteção internacional dos Direitos da Pessoa Humana, San José da Costa Rica: IIDH, Comitê Internacional da Cruz Vermelha, Alto Comissariado das Nações Unidas para os Refugiados, 1996.

DIHN, Ngunyen Quoc. DAILLIER, Patrick; PELLET, Alain. Direito internacional público. Fundação Calouse Gulbenkian. 1999.

FERNANDES, Jean Marcel. A promoção da paz pelo direito internacional humanitário. Porto Alegre: Editora Sérgio Fabris, 2006.

FISCHEL DE ANDRADE, J.H. "El Sistema Africano de Protección de los Derechos Humanos y de los Pueblos", in A.A. Cançado Trindade et al. (comp.), Estudios Básicos de Derechos Humanos, tomo VI, San José de Costa Rica, Instituto Interamericano de Derechos Humanos, 1996, pp. 490-491.

HERRERA FLORES, Joaquín, La reinvención de los derechos humanos. Sevilla: Colección Ensayando, 2007.

JARDIM, Tarciso dal Maso, $O$ Brasil e o direito internacional dos conflitos armados, Tomo I. Porto Alegre: Editora Sérgio Antonio Fabris, 2006.

KRIEGER, César Amorin. Direito Internacional Humanitário: o precedente do Comitê Internacional da Cruz Vermelha e o Tribunal Penal Internacional. Curitiba: Juruá, 2005.
MELLO, Celso D. de Albuquerque. O $\S 2^{\circ}$ do art. $5^{\circ}$ da Constituição Federal. In: TORRES, Ricardo Logo (Org.). Teoria dos direitos fundamentais. Rio de Janeiro: Renovar, 1999.

PETIT DE GABRIEL, Eulália W. Las exigências de humanidad en el derecho internacional tradicional (1789-1939). Madrid: Tecnos, 2003.

PIOVESAN, Flávia. Direitos humanos e o direito constitucional internacional. 6.ed. São Paulo: Max Limonad, 2004.

PRONER, Carol. Direitos humanos e seus paradoxos: analise do sistema americano de proteção. Porto Alegre: Fabris, 2002.

PRONER, C., GUERRA, S. (Organizadores) Direito internacional humanitário e a proteção internacional do indivíduo . Porto Alegre: Fabris, 2008.

PRONER, C. RICOBOM, G. O Brasil e o direito humanitário: atuação do Comitê Internacional da Cruz Vermelha e regulamentação do Tribunal Penal Internacional. Em Direito internacional humanitário e a proteção internacional do indivíduo (Proner, C., Guerra, S. Organizadores). Porto Alegre: Fabris, 2008.

REZEK, Francisco. Direito internacional público: curso elementar. 10.ed. São Paulo: Saraiva, 2005.

TEITELBAUM, Alejandro. La crisis actual del derecho al desarrollo. Deusto: Universidad de Deusto. Instituto de Derechos Humanos. 2001.

VALLADARES, Gabriel Pablo. A contribuição do Comitê Internacional da Cruz Vermelha (CICV) aos últimos avanços convencionais do direito internacional humanitário. Em Direito internacional humanitário e a proteção internacional do indivíduo (Proner, C., Guerra, S. Organizadores). Porto Alegre: Fabris, 2008.

VOS, Pierre de. Um nouveau commencement? L'application des droits sociaux, économiques et culturels de la charte africaine sur les droits des humains et des peuples. En Les droits sociaux fondamentaux à l'âge de la mondialisation. Aix-en-Provence: Presses Universitaires, 2005. 